\title{
Microbiological Study of Vaginal Microbiota and Endometrium in Women with Chronic Endometritis
}

\author{
Natalia M. Voropaeva*; Lyudmila M. Lazareva, PhD; Irina N. Danusevich, PhD, ScD; \\ Natalia L. Belkova, PhD; Uliana M. Nemchenko, PhD; Ekaterina V. Grigorova, PhD \\ Scientific Centre for Family Health and Human Reproduction Problems \\ Irkutsk, the Russian Federation
}

\begin{abstract}
The research objective was to study the spectrum of the vagina and endometrium microorganisms in women with chronic endometritis (CE) in order to take adequate therapeutic measures.

Methods and Results: We did a cross-sectional study in 47 women (average age of $35.38 \pm 5.19$ years) with histologically confirmed CE. The vaginal microbiota and endometrial biopsies were assessed using microbiological research methods in accordance with the medical technology "Integral assessment of the state of the vaginal microbiota." To identify the share of different types of microorganisms in the structure of the biocenosis, the coefficient of constancy of the species (C) was used.

Only $19 \%$ of patients had a titer of Lactobacillus spp. within the age norm, while the deficit was observed in $80 \%$ of women. Among the representatives of Enterobacteriaecae, Escherichia coli and Klebsiella aerogenes were sown, which are considered to be random species $(\mathrm{C}=11 \%$ and $\mathrm{C}=2.1 \%$, respectively). The average titer for $E$. coli was $3.6 \pm 1.3 \mathrm{lg} \mathrm{CFU} / \mathrm{swab}$ and for $K$. aerogenes $2.14 \mathrm{lg}$ CFU/swab. An atypical variant of $E$. coli with hemolytic properties was found in only one sample. All isolates of the genus Staphylococcus were also random species (C did not exceed 25\%). Coagulase-negative staphylococci (CoNS) were detected in 7 patients $(\mathrm{C}=15 \%)$, while the average titer was $2.1 \pm 0.4 \mathrm{lg} \mathrm{CFU} / \mathrm{swab}$. $S$. aureus was isolated from only one patient at a titer of 5 $\lg \mathrm{CFU} / \mathrm{swab}$. Corynebacterium spp. were isolated in $11 \%$ of cases $(\mathrm{C}=11 \%$ - random species), in a titer of $3.2 \pm 0.8 \mathrm{lg} \mathrm{CFU} / \mathrm{swab}$. Enterococcus spp. also belonged to random species $(\mathrm{C}=23.4 \%)$. At the same time, E. faecalis was inoculated in $19 \%$ of cases and E. faecium was sown in $4.3 \%$, the average titer of which was $3.1 \pm 0.9$ and $5 \mathrm{lg}$ CFU/swab. Streptococcus spp. were recorded in only one case at a concentration of $5 \mathrm{lg} \mathrm{CFU} / \mathrm{swab}$. Fungi of the Candida were isolated as a random species in $8.5 \%$ of cases. The growth of microorganisms in endometrial samples was obtained only in 3 examined women with CE (6.4\% of cases). The endometrial microbiota were represented only by random species, for which the $\mathrm{C}$ index ranged from $2.1 \%$ to $4.3 \%$.

Conclusion: The microbiological study of the microbiota of vaginal discharge showed the presence of dysbiotic disorders with a significant deficiency of lactobacilli $(80 \%)$ without the dominance of representatives of the Lactobacillus spp. In the structure of opportunistic microflora, Escherichia coli, coagulase-negative staphylococcus, Enterococcus spp., and E. faecalis prevailed as random species. Representatives of the microbiota in endometrial biopsies were identified only in $6.4 \%$ of cases, and are represented by random species. (International Journal of Biomedicine. 2021;11(4):511-514.)
\end{abstract}

Key Words: chronic endometritis $\bullet$ microbiota $\bullet$ vagina $\bullet$ endometrium

For citation: Voropaeva NM, Lazareva LM, Danusevich IN, Belkova NL, Nemchenko UM, Grigorova EV. Microbiological Study of Vaginal Microbiota and Endometrium in Women with Chronic Endometritis. International Journal of Biomedicine. 2021;11(4):511-514. doi:10.21103/Article11(4)_OA17

\section{Abbreviations}

CE, chronic endometritis; CPB, conditionally pathogenic bacteria; CFU, colony-forming units; CoNS, coagulase-negative staphylococci; STIs, sexually transmitted infections.

\section{Introduction}

Chronic endometritis (CE) is a clinical and morphological syndrome, in which, as a result of persistent damage to the endometrium by an infectious agent, multiple secondary morphofunctional changes occur, disrupting cyclic biotransformation and receptivity of the mucous membrane of the uterine body. ${ }^{(1)} \mathrm{CE}$ is detected in about $10 \%$ to $21 \%$ 
of women of reproductive age, and its presence is associated with infertility and miscarriage. ${ }^{(2-10)}$

For a long time, the uterine cavity was considered a sterile biotope. $^{(2)}$ However, at present, the use of molecular genetic research methods makes it possible to identify associations of difficult-to-cultivate and uncultured microorganisms on the surface of the endometrium in women of reproductive age. ${ }^{(11-16)}$ There are no concurrent views on the influence of certain groups of conditionally pathogenic bacteria (CPB) on the development of the endometrium inflammatory pathology, and this raises doubts about the advisability of prescribing antimicrobial therapy for CE..$^{(4,17-19)}$ For a more complete assessment of the state of the vaginal microbiota, it is necessary not only to assess the total quantitative characteristics of Lactobacillus spp., but also to determine the species composition and functional parameters of lactobacilli in various gynecological diseases. ${ }^{(20)}$

The research objective was to study the spectrum of the vagina and endometrium microorganisms in women with $\mathrm{CE}$ in order to take adequate therapeutic measures.

\section{Materials and Methods}

From 2020 to the present, we have been conducting a cross-sectional study under the auspices of the Scientific Centre for Family Health and Human Reproduction Problems. Our study included 47 women with histologically confirmed CE. The average age of the patients was $35.38 \pm 5.19$ years. Inclusion criteria were the presence of histologically verified $\mathrm{CE}$, reproductive age (18-45 years). Exclusion criteria were the use of antibacterial, hormonal, or immunomodulatory drugs, and the presence of STIs.

The patients were included in the study after signing a written informed consent. All women who agreed to participate answered a questionnaire survey and underwent general clinical, gynecological, and laboratory-instrumental examination. The sampling of material from the uterine cavity was made on the fourth to ninth day of the menstrual cycle (middle proliferative phase) using a pipelle biopsy of the endometrium with a disposable intrauterine probe (Taizhou Kechuang Medical Apparatus Co., Ltd, China), followed by pathological examination of the endometrial tissue for verification of CE signs.

The vaginal microbiota and endometrial biopsies were assessed using microbiological research methods in accordance with the medical technology "Integral assessment of the state of the vaginal microbiota."(21) Vaginal discharge and endometrial biopsy homogenate were inoculated on standard culture media; CFU were counted. Microbiota were identified through the use of standardized bacteriological algorithms, taking into account morphological, cultural and biochemical properties.

To identify the share of different types of microorganisms in the structure of the biocenosis, the coefficient of constancy of the species (C) was used according to the formula: $\mathrm{C}=\mathrm{p}$ $\times 100 / \mathrm{P}$, where $\mathrm{p}$ is the number of observations containing the studied species, $\mathrm{P}$ is the total number of observations. At values of $C \geq 50 \%$, microorganisms were considered constant; at values of $25 \% \leq \mathrm{C} \leq 50 \%$ they were considered additional; at values of $\mathrm{C}<25 \%$ they were considered random. ${ }^{(22)}$

All data have been entered into the REDCap system. Statistical processing was carried out using the STATISTICA Version 6.1 (StatSoft USA). Baseline characteristics were summarized as frequencies and percentages for categorical variables and as mean $\pm \mathrm{SD}$ for continuous variables.

The study was carried out in compliance with Ethical Principles for Medical Research Involving Human Subjects, Adopted by the 18th WMA General Assembly, Helsinki, Finland, June 1964, and amended by the 64th WMA General Assembly, Fortaleza, Brazil, October 2013. The study was approved by the Ethics Committee of the Scientific Center for Family Health and Human Reproduction Problems. Written informed consent was obtained from each participant.

\section{Results and Discussiom}

According to the results of the microbiological study of vaginal discharge in women with CE, Lactobacillus spp. were identified as permanent representatives of the vaginal microbiota $(\mathrm{C}=79 \%)$. Moreover, only $19 \%$ of patients had a titer of Lactobacillus spp. within the age norm, while the deficit was observed in $80 \%$ of women. Bacterial vaginal communities dominated by Lactobacillus spp. have been considered for a long time a sign of vaginal health. ${ }^{(2,23,24)}$ Among the representatives of the genus Lactobacillus, L. crispatus, L. gasseri, L. iners, and $L$. jensenii dominate in the vaginal microbiota of healthy women. The prevalence of $L$. crispatus indicates the stability of the vaginal microbiota, as this species produces lactic acid, hydrogen peroxide and bacteriocins. L. iners is a marker of vaginal dysbiotic disorders. This species does not produce lactic acid and hydrogen peroxide, which are necessary for maintaining eubiosis and cannot provide a transition to the prevalence of $L$. crispatus. ${ }^{(25)}$ Due to the structure of the genome, L. iners is able to quickly adapt to changing environmental conditions, switching its metabolism and using other substances, not glycogen, as food resources. Thus, under conditions of dysbiosis, L. iners produces cholesterol-dependent cytolysin, which destroys cell walls, and uses glycerol of destroyed cell membranes as a new food substrate. This leads to the death of other species of Lactobacillus spp., a decrease in the concentration of lactic acid and an increase in the $\mathrm{pH}$ of the vaginal environment. ${ }^{(26)}$ The significance and role of $L$. gasseri and L. jensenii species in maintaining the normal state of the vaginal microbiota still remain controversial. ${ }^{(20)}$

Among the representatives of Enterobacteriaecae, Escherichia coli and Klebsiella aerogenes were sown, which are considered to be random species $(\mathrm{C}=11 \%$ and $\mathrm{C}=2.1 \%$, respectively). The average titer for $E$. coli was $3.6 \pm 1.3 \mathrm{lg} \mathrm{CFU} /$ swab and for $K$. aerogenes - $2.14 \mathrm{lg}$ CFU/swab. An atypical variant of $E$. coli with hemolytic properties was found in only one sample. Vaginal discharge of such intestinal biotope residents as enterobacteria confirms the translocation of microorganisms from the intestine against the background of immunodeficiency in women with chronic endometrial inflammation. ${ }^{(27)}$

All isolates of the genus Staphylococcus were also random species (C did not exceed 25\%). Coagulase-negative 
staphylococci (CoNS) were detected in 7 patients $(\mathrm{C}=15 \%)$, while the average titer was $2.1 \pm 0.4 \mathrm{lg} \mathrm{CFU} / \mathrm{swab}$. S. aureus was isolated from only one patient at a titer of $5 \mathrm{lg}$ CFU/swab. CoNS are part of the normal vaginal microbiota; however, under certain conditions, lactobacilli are not able to suppress the growth and production of toxins by staphylococci. The increase in $\mathrm{pH}$ created by the violation of the microbiota ratio promotes the production of $S$. aureus toxins. ${ }^{(20)}$

Corynebacterium spp. were isolated in $11 \%$ of cases $(\mathrm{C}=11 \%$ - random species), in a titer of $3.2 \pm 0.8 \mathrm{lg} \mathrm{CFU} /$ swab. Enterococcus spp. also belonged to random species $(\mathrm{C}=23.4 \%)$. At the same time, E. faecalis was inoculated in $19 \%$ of cases and E. faecium was sown in $4.3 \%$, the average titer of which was $3.1 \pm 0.9$ and $5 \mathrm{lg}$ CFU/swab. Streptococcus spp. were recorded in only one case at a concentration of 5 $\lg$ CFU/swab. Streptococci are glycogen-dependent bacteria, which ensures their successful colonization of the vaginal epithelium, thereby creating competition for lactobacilli. Despite the fact that these microorganisms are part of the normal vaginal microbiota, their presence, even as an accidental one, can contribute to the development of dysbiotic disorders. Also, changes in the composition of the vaginal microbiota can lead to the spread of opportunistic microflora in the upper genital tract and contribute to the development of infertility. ${ }^{(28)}$

Fungi of the Candida were isolated as a random species in $8.5 \%$ of cases. The average titer was $4.0 \pm 0.8 \mathrm{lg}$ CFU/swab.

The growth of microorganisms in endometrial samples was obtained only in 3 examined women with CE (6.4\% of cases). The endometrial microbiota were represented only by random species, for which the $\mathrm{C}$ index ranged from $2.1 \%$ to $4.3 \%$. Moreover, Lactobacillus spp. titer was $4 \mathrm{lgCFU} /$ swab, for E. coli (one isolate) - $3 \mathrm{lg} \mathrm{CFU} / \mathrm{swab}, E$. faecalis (2 isolates) - $3.5 \pm 0.7 \mathrm{lg} \mathrm{CFU} / \mathrm{swab}$. Only one case, E. faecalis, was sown both from the vagina and from endometrial samples. It is possible to assume that the presence of these types of CPB probably indicates an upward spread of the infectious process.

\section{Conclusion}

Thus, in women with CE, a microbiological study of the microbiota of vaginal discharge showed the presence of dysbiotic disorders with a significant deficiency of lactobacilli $(80 \%)$ without the dominance of representatives of the Lactobacillus spp. In the structure of opportunistic microflora, Escherichia coli, coagulase-negative staphylococcus, Enterococcus spp., and $E$. faecalis prevailed as random species. Representatives of the microbiota in endometrial biopsies were identified only in $6.4 \%$ of cases, and are represented by random species.

Our study is a pilot. The limitation of our study is that the sample is not large enough to obtain more significant results and understand the role of changes in the microbiota of the vagina and endometrium in the development of $\mathrm{CE}$.

This work was performed with the use of equipment of the collective research center "Centre for the development of progressive personalized health technologies" SC FHHRP, Irkutsk.

\section{Acknowledgments}

This article contains material that has been discussed at the VIII International Research and Practical Conference "FUNDAMENTAL AND APPLIED ASPECTS OF REPRODUCTION" (December 2021, Irkutsk, Russia). The author thanks all researchers who participated in the oral discussion.

\section{Conflict of Interests}

The authors declare that they have no conflicts of interest.

\section{References}

1. Shurshalina AV. [Chronic endometritis: modern views on the problem]. Consilium Medicum. 2011;13(6)36-39. [Article in Russian].

2. Ailamazyan EK, Kulakova VI, Radzinsky VE, Savelyeva GM. Obstetrics: national guidance: M, GEOTAR-Media; 2007. [In Russian]

3. Cicinelli E, Matteo M, Tinelli R, Pinto V, Marinaccio M, Indraccolo U, De Ziegler D, Resta L. Chronic endometritis due to common bacteria is prevalent in women with recurrent miscarriage as confirmed by improved pregnancy outcome after antibiotic treatment. Reprod Sci. 2014 May;21(5):640-7. doi: $10.1177 / 1933719113508817$.

4. Cicinelli E, Resta L, Nicoletti R, Tartagni M, Marinaccio M, Bulletti C, Colafiglio G. Detection of chronic endometritis at fluid hysteroscopy. J Minim Invasive Gynecol. 2005 NovDec;12(6):514-8. doi: 10.1016/j.jmig.2005.07.394.

5. Kushnir VA, Solouki S, Sarig-Meth T, Vega MG, Albertini DF, Darmon SK, Deligdisch L, Barad DH, Gleicher N. Systemic Inflammation and Autoimmunity in Women with Chronic Endometritis. Am J Reprod Immunol. 2016 Jun;75(6):672-7. doi: 10.1111/aji.12508.

6. Yang R, Du X, Wang Y, Song X, Yang Y, Qiao J. The hysteroscopy and histological diagnosis and treatment value of chronic endometritis in recurrent implantation failure patients. Arch Gynecol Obstet. 2014 Jun;289(6):1363-9. doi: 10.1007/s00404-013-3131-2.

7. Cicinelli E, Matteo M, Tinelli R, Lepera A, Alfonso R, Indraccolo U, Marrocchella S, Greco P, Resta L. Prevalence of chronic endometritis in repeated unexplained implantation failure and the IVF success rate after antibiotic therapy. Hum Reprod. 2015 Feb;30(2):323-30. doi: 10.1093/humrep/ deu292.

8. Johnston-MacAnanny EB, Hartnett J, Engmann LL, Nulsen JC, Sanders MM, Benadiva CA. Chronic endometritis is a frequent finding in women with recurrent implantation failure after in vitro fertilization. Fertil Steril. 2010 Feb;93(2):437-41. doi: 10.1016/j.fertnstert.2008.12.131.

9. Baeva AV, Leshchenko YaA, Kuleshova MV, Leshchenko OYa, Cherkashin AK. Family and demographic processes in the Irkutsk region. Irkutsk, 2017: 212. [In Russian]

\footnotetext{
*Corresponding author: Natalia M. Voropaeva Scientific Centre for Family Health and Human Reproduction Problems, Irkutsk, the Russian Federation.E-mail: n.m.shabanova@mail.ru
} 
10. Leshchenko OYa, Genich EV. [Reproductive disorders and their pathogenetic mechanisms in HIV-infected women]. HIV Infection and Immunosuppression. 2019;11(4):20-29. doi: 10.22328/2077-9828-2019-11-4-20-29. [Article in Russian]. 11. Moreno I, Codoñer FM, Vilella F, Valbuena D, MartinezBlanch JF, Jimenez-Almazán J, Alonso R, Alamá P, Remohí J, Pellicer A, Ramon D, Simon C. Evidence that the endometrial microbiota has an effect on implantation success or failure. Am J Obstet Gynecol. 2016 Dec;215(6):684-703. doi: 10.1016/j. ajog.2016.09.075.

12. Moreno I, Franasiak JM. Endometrial microbiota-new player in town. Fertil Steril. 2017 Jul;108(1):32-39. doi: 10.1016/j.fertnstert.2017.05.034.

13. Baker JM, Chase DM, Herbst-Kralovetz MM. Uterine Microbiota: Residents, Tourists, or Invaders? Front Immunol. 2018 Mar 2;9:208. doi: 10.3389/fimmu.2018.00208.

14. Peric A, Weiss J, Vulliemoz N, Baud D, Stojanov M. Bacterial Colonization of the Female Upper Genital Tract. Int J Mol Sci. 2019 Jul 11;20(14):3405. doi: 10.3390/ ijms20143405.

15. Tsypurdeeva ND, Shipitsyna EV, Savicheva AM, Gzgzyan AM, Kogan IYu. [The composition of the endometrial microbiota and the severity of chronic endometritis in patients with ineffective in vitro fertilization protocols. Is there a connection?] Journal of Obstetrics and Women's Diseases. 2018;67(2):5-15. doi: 10.17816/JOWD6725-15. [Article in Russian].

16. Espinoza J, Erez O, Romero R. Preconceptional antibiotic treatment to prevent preterm birth in women with a previous preterm delivery. Am J Obstet Gynecol. 2006 Mar;194(3):6307. doi: 10.1016/j.ajog.2005.11.050.

17. Danusevich IN, Ivanova EI, Mikhalevich IM. [Characteristics of the microbiocenosis of the vaginal tract and its role in initiating inflammatory process in endometrium in women with reproductive disorders]. Acta Biomedica Scientifica. 2017;2(5(2)):15-20. doi: 10.12737/article_5a3a0d 6243ea24.16475434. [Article in Russian].

18. Leshchenko OYa. [Chronic endometritis and reproductive disorders: version and con traversion]. Bulletin of Siberian Medicine. 2020;19(3):166-176. https://doi.org: 10.20538 / 1682-0363-2020-3-166-176. [Article in Russian].

19. Danusevich IN, Sharifulin EM, Nemchenko UM, Lyubov I. Kolesnikova LI. Features of the Immune System Functioning with Persistence of Infectious Agents in Women with Chronic Endometrial Inflammation and Reproductive Disorders.
International Journal of Biomedicine. 2020;10(4):362-368. doi: 10.21103/Article10(4)_OA6

20. Godovalov AP, Gushchin MO, Karpunina TI. [Features of intermicrobial relations in the vaginal microbiota of infertile women]. Medical Bulletin of the North Caucasus. 2019;14(1.1):40-44. doi: 10.14300/mnnc.2019.14045 [Article in Russian].

21. Ankirskaya AS, Muravyova VV.[ Integral assessment of the conditione of the vaginal microbiota. Diagnosis of opportunistic vaginitis]. Akusherstvo i Ginekologiya: Novosti, Mneniya, Obuchenie. 2020;8(1);69-76. doi: 10.24411/ 23039698-2020-11009. [Article in Russian].

22. ZakharovaEA,Azizov IS. [Microecological characteristics of the intestinal microbiocenosis of frequently ill children]. Microbiol Journal. 2012;2:63-68. [Article in Russian].

23. Tamrakar R, Yamada T, Furuta I, Cho K, Morikawa M, Yamada H, Sakuragi N, Minakami H. Association between Lactobacillus species and bacterial vaginosis-related bacteria, and bacterial vaginosis scores in pregnant Japanese women. BMC Infect Dis. 2007 Nov 7;7:128. doi: 10.1186/1471-23347-128.

24. Smith SB, Ravel J. The vaginal microbiota, host defence and reproductive physiology. J Physiol. 2017 Jan 15;595(2):451-463. doi: 10.1113/JP271694.

25. Budilovskaya OV. [Modern ideas about the vagina lactobacilli in women of reproductive age]. Journal of Obstetrics and Women's Diseases. 2016;LXV(4):34-43.doi: 10.17816/JOWD6534-43. [Article in Russian].

26. Dicke GB. Bacterial vaginosis: new aspects of etiopathogenesis and choice of therapeutic strategies. RZhM. Mother and Child. 2019;2(4):307-313. doi: 10.32364/26188430-2019-2-4-307-313

27. Kungurtseva EA, Belkova NL, Prefix AA, Ivanova EI, Darenskaya MA, Serdyuk LV, Leshchenko OYa. [The structure of the opportunistic microbiota of the nasopharynx and vaginal tract in women with reproductive disorders and chronic endometritis]. Klinicheskaya Laboratornaya Diagnostika. 2017;62(4):252-256. doi: 10.18821/0869-20842017-62-4-252-256 [Article in Russian].

28. Babu G, Singaravelu BG, Srikumar R, Reddy SV, Kokan A. Comparative Study on the Vaginal Flora and Incidence of Asymptomatic Vaginosis among Healthy Women and in Women with Infertility Problems of Reproductive Age. J Clin Diagn Res. 2017 Aug;11(8):DC18-DC22. doi: 10.7860/ JCDR/2017/28296.10417. 